\title{
Subjective health complaints in older adolescents are related to perceived stress, anxiety and gender - a cross-sectional school study in Northern Sweden
}

Maria Wiklund ${ }^{1,2 *}$, Eva-Britt Malmgren-Olsson², Ann Öhman ${ }^{1,3}$, Erik Bergström ${ }^{4}$ and Anncristine Fjellman-Wiklund ${ }^{2}$

\begin{abstract}
Background: Negative trends in adolescent mental and subjective health are a challenge to public health work in Sweden and worldwide. Self-reported mental and subjective health complaints such as pain, sleeping problems, anxiety, and various stress-related problems seem to have increased over time among older adolescents, especially girls. The aim of this study has therefore been to investigate perceived stress, mental and subjective health complaints among older adolescents in Northern Sweden.

Methods: Data were derived from a cross-sectional school-based survey with a sample consisting of 16-18 year olds ( $n=1027)$, boys and girls, in the first two years of upper secondary school, from different vocational and academic programmes in three public upper secondary schools in a university town in northern Sweden. Prevalence of perceived stress, subjective health complaints, general self-rated health, anxiety, and depression were measured using a questionnaire, including the Hospital Anxiety and Depression Scale (HADS).

Results: A large proportion of both girls and boys reported health complaints and perceived stress. There was a clear gender difference: two to three times as many girls as boys reported subjective health complaints, such as headache, tiredness and sleeping difficulties and musculoskeletal pain, as well as sadness and anxiety. High pressure and demands from school were experienced by $63.6 \%$ of girls and $38.5 \%$ of boys. Perceived stress in the form of pressure and demands correlated strongly with reported health complaints $(r=0.71)$ and anxiety $(r=0.71)$.

Conclusions: The results indicate that mental and subjective health complaints are prevalent during adolescence, especially in girls, and furthermore, that perceived stress and demands may be important explanatory factors. Future studies should pay attention to the balance between gender-related demands, perceived control and social support, particularly in the school environment, in order to prevent negative strain and stress-related ill-health. The gender gap in subjective adolescent health needs to be further explored.
\end{abstract}

Keywords: Sweden, Adolescent, School students, Self-reported health, Psychosomatic, Stress, Pain, Mental health, Anxiety, Depression

\footnotetext{
* Correspondence: maria.wiklund@physiother.umu.se

'Umeå Center for Gender Studies, Umeå University, Umeå, Sweden

${ }^{2}$ Department of Community Medicine and Rehabilitation, Physiotherapy,

Umeå University, Umeå, Sweden

Full list of author information is available at the end of the article
} 


\section{Background}

Adolescent mental and subjective health has become a public health concern in Sweden and worldwide [1-4]. In Sweden, self-reported mental and subjective health complaints, such as pain, sleeping problems, anxiety, and various stress-related problems are common and seem to have increased over time among older adolescents, especially girls [5-9]. Similar trends are found across the Nordic countries, the rest of Europe, and North America indicating the need to address sociocontextual factors in the study of gender health inequalities during adolescence [10-13]. However, time trends are found to be discrepant and subject to change $[5,6]$. For example, a study from 2004 observed a rise of conduct- and emotional problems in UK adolescents over a 25-years period [14]; whereas more recent ratings indicated that children's mental health problems now may have "peaked" [15]. In comparison, a national Dutch study shows divergent trends in adolescent mental health in terms of sex/gender with a decline in boys' externalization problems, but an increase in girls' internalization problems [16].

In Sweden, adolescents' "stress" and mental health are now on the public health agenda [7,17]. Repeated Internet-based surveys found that perceived stress and psychosomatic health problems peak in adolescent girls at $16-18$ years of age [8]. In this age group $37 \%$ of the girls and $22 \%$ of the boys considered themselves as being "very often" stressed. Also the longitudinal national Survey of living conditions among children shows high prevalence of self-reported stress in female upper secondary school students [18]. In a sample of 16-year old upper secondary school students in Stockholm, one-third reported serious stress-symptoms with $14.2 \%$ of the girls and $2.6 \%$ of the boys exceeding the set cut-off for chronic stress [19]. Perceptions of high demands, low global self-esteem, sleep disturbances and poor social support seemed to predict their stress symptoms.

In line with these empirical findings, adolescence in industrialized countries is commonly described as an important period of development characterized by tumultuous transition and "storm and stress" - although such notions also are questioned [20-22]. During adolescence, health and resilience develop in a manner closely linked to the social context such as family, peers, partners and school. However, this period can also be a time of psychological distress [19,23-27]. Adolescence is viewed as a critical period for early onset of mental illness [28]. Despite being heterogeneous as a group, adolescents share rapid physical, cognitive, emotional and social changes [21,29]. Adolescents' health related quality of life is found to be influenced by development of self-governance and autonomy, position in peer-group, intimacy and sexuality as well as by physical maturation and a changing body [29]. Late adolescence can be a lonely time in life, with what is often a concomitant increase in various stressors and demands [21,29,30]. Adolescent stress appears to be linked to multiple stressors and areas such as school performance, partner relationships, bullying and peer pressure, financial problems, emerging adult responsibilities and worries about the future $[21,31]$. When placing these aspects in a wider social context, young people's lives and challenges seem even more complex [31,32]. Social aspects of gender are also seen as interlinked with experienced stress and health-problems $[31,33,34]$. "Gendered pathways in school burnout" is a recently raised topic in research on adolescent stress [13].

Co-occurrence of physical and psychological health problems is common among adolescents [35] and associations between various stressors, perceived stress and subjective health complaints have been observed $[24,36]$. Frequent subjective health problems are headache, abdominal pain, musculoskeletal symptoms, sleeping difficulties and nervousness [37]. Multiple pain problems, as an example, have negative psychosocial consequences and impact on quality of life [38]. In addition, pain problems often persist into early adulthood [39]. Adolescent sleep disturbances are also found to predict sleeping disturbances later in life [40,41]. Moreover, longitudinal studies indicate that mild psychiatric symptoms early in life such as anxiety, insomnia or sub-threshold depression increase the risk of psychiatric conditions later in life [42-44].

These negative trends in adolescent health development are a challenge to public health work, as well as to society at large [2,9]. Explanatory factors regarding decreased subjective wellbeing and health complaints in young people have largely yet to be explored, especially the explanation behind the striking gender differences $[9,10]$. A number of epidemiological studies have been conducted among Swedish children and adolescents in primary and lower secondary schools, including some in northern Sweden [5,26,45-47], but studies among older adolescents are still scarce in the Umeå region. The aim of this study is to investigate the prevalence of perceived stress, mental and subjective health complaints - including possible differences between boys and girls - among upper secondary school adolescents in northern Sweden.

\section{Methods}

\section{Study setting and procedure}

This cross-sectional school study is part of a larger research project, Stress and Health among Youth in Northern Sweden (Umeå SHY), the purpose of which is to study stress, body and health among young people; and to develop and evaluate health-promotion intervention models within youth- and school health services. The project is a collaboration initiative between 
the university, the county council and the municipality in the region. The setting is the municipality of Umeå, a university city in northern Sweden with about 100000 inhabitants. In Umeå there are both public and private upper secondary schools. At the time of the study $76 \%$ of students in the municipality attended public upper secondary schools, with $53 \%$ girls and $47 \%$ boys (School Statistics).

In 2007-2008, a classroom survey was conducted at three of the major public schools in Umeå municipality. The reason for this sample was to establish a baseline reference for a stress-management intervention conducted at the same schools. Each school offered a range of academic and vocational secondary school programmes. Vocational programmes were, and still are, directed towards work in areas such as the building-, service-, or health sectors which, not demand higher education. In contrast, academic programmes aim to prepare students for higher academic education in fields such as economics, media, the arts and the natural or social sciences.

The study was conducted in close cooperation with the school health services. Prior to the survey, the main heads of school were contacted, and granted permission for the classroom survey. All primary teachers at each educational programme and class were informed and invited to participate with their respective class. Teachers who expressed an interest were then contacted and arranged time for the survey. Before participation, students received written and oral information about the study, including information about confidentiality and the right not to participate. Information was also available to adolescents and parents on the schools' Internet homepages. The survey was supervised by a member of the research team who also answered questions from the students. The questionnaire took about 30 minutes to complete, and was finished during a school lesson. The questionnaire was anonymous and no records or codes were obtained. The study was approved by the Regional Ethical Review Board in Umeå, Sweden (Dnr 05-045 M).

\section{Sampling and participants}

There were a total of 2721 students in the first two years of upper secondary school at the three invited schools: $53 \%$ girls and $47 \%$ boys; $69 \%$ in academic programmes and $31 \%$ in vocational programmes. For practical reasons, 1545 of the students were not available to participate in the survey because of absence due to internship outside of school (vocational programmes), or because their teachers did not answer our invitation or had no possibility of allocating time for the classroom survey. Questionnaires were thus administered to 1176 students across 49 classes. In total, 1033 of these students answered the questionnaire, which resulted in a response rate of $87.8 \%$ in the participating classes. Nonparticipation was due to absence from school on the day the questionnaire was administered $(n=132)$. Answers from six students were excluded because they fell outside the selected sample of 16-18-year-olds: 15 years $(n=2), 19$ years $(n=2)$ and 20 years $(n=2)$. Five questionnaires were excluded due to missing data. In total, 1027 questionnaires were included in the analysis.

\section{Measures}

The questionnaire consisted of both established instruments and questions formulated specifically for this study. Questions covered socio-demographics, subjective health complaints, perceived stress [48], sleep, general self-rated health, medication, anxiety and depression $[49,50]$. The questionnaire comprises more areas than analyzed in the present study.

\section{Socio-demographics}

Socio-demographics were described by sex, age, educational programme, family situation and country of birth.

\section{Subjective health complaints}

Subjective health complaints was measured with a 16-item symptom checklist consisting of musculoskeletal pain in different parts of the body, headache, stomach and heart symptoms, symptoms of upper respiratory infection, tiredness/fatigue, nausea, dizziness and sadness. Six-month symptom prevalence was estimated through the question: "In the past six months, have you had the following problem?" Response alternatives were "never", "seldom", "sometimes", "fairly often" and "very often". For data analysis $\left(\mathrm{Chi}^{2}\right.$ tests) the response alternatives were trichotomized as "never/seldom", "sometimes" and "fairly often/very often".

The factor analysis on subjective health complaints yielded three factors with eigenvalues greater than one (Table 1). The first factor was termed "psychosomatic symptoms" and consisted of five items (eigenvalue 6.07, Cronbach's alpha 0.77). The second factor was named "headache/upper respiratory infection symptoms" and consisted of four items (eigenvalue 1.33, Cronbach's alpha 0.75 ). The third factor was termed "musculoskeletal pain symptoms" and consisted of four items (eigenvalue 1.16, Cronbach's alpha 0.76) (Table 1). Selected factors with an eigenvalue greater than 1 explained $53.5 \%$ of the variance. Three items (dizziness, stomach pain and sleeping problems) did not reach factor loading $>0.5$ and were therefore excluded. 
Table 1 Factor analysis using a rotated component matrix for subjective health complaint variables (factor loading $>0.50$ is cut-off point for inclusion)

\begin{tabular}{|c|c|c|c|}
\hline \multirow[t]{2}{*}{ Subjective health complaint variables } & \multicolumn{3}{|c|}{ Factor loading } \\
\hline & Factor 1 & Factor 2 & Factor 3 \\
\hline Psychosomatic symptoms & nbach's alpha 0.77 & & \\
\hline More tired than before & 0.560 & & \\
\hline Sadness & 0.659 & & \\
\hline Acid stomach, stomach ache & 0.667 & & \\
\hline Pain and aches in heart and chest & 0.692 & & \\
\hline Palpitations and extra heart beats & 0.678 & & \\
\hline Headache/upper respiratory infection symptoms & & Eigenvalue 1.33 Cronbach's alpha 0.75 & \\
\hline Headache & & 0.526 & \\
\hline Cold symptoms & & 0.799 & \\
\hline Cough and hoarseness & & 0.793 & \\
\hline Nausea & & 0.539 & \\
\hline Musculoskeletal pain symptoms & & & $\begin{array}{c}\text { Eigenvalue } 1.16 \text { Cronbach's } \\
\text { alpha } 0.76\end{array}$ \\
\hline Neck and shoulder pain & & & 0.616 \\
\hline Low back pain & & & 0.690 \\
\hline Pain in extremity joints & & & 0.774 \\
\hline Muscle pain & & & 0.754 \\
\hline
\end{tabular}

Selected factors with an eigenvalue greater than 1 explained $53.5 \%$ of the variance.

\section{Perceived stress including sleep}

Perceived stress was measured using a stress instrument developed by Lindblad et al. [48]. The instrument includes 16 items: 12 items on perceived stress and four items on sleep. Recall time was the previous weeks. Response alternatives were "never", "seldom", "sometimes", "often", and "always". For data analysis $\left(\mathrm{Chi}^{2}\right.$ tests), response alternatives were trichotomized as "never/seldom", "sometimes" or "often/always".

The factor analysis on perceived stress and sleep yielded three factors (Table 2). The first factor, "pressure and demands" included seven items (eigenvalue 5.97, Cronbach's alpha 0.83). The second factor, "activation/high tempo" included five items (eigenvalue 1.41, Cronbach's alpha 0.72). The third factor, "sleep problems" included four items (eigenvalue 1.04, Cronbach's alpha 0.82). Selected factors with an eigenvalue greater than 1 explained $52.7 \%$ of the variance.

\section{General self-rated health}

General self-rated health was measured using one statement "I perceive my health as" with four response alternatives: "very good", "fairly good", "not quite good" and "not good at all". The response alternatives were dichotomized into good ("very good/ fairly good") and bad ("not quite good/not good") health. The question about self-reported health is similar to the question used by Breidablik, Meland and Lydersen in a cross-sectional study of 16 to 20 years old Norwegian students [51].

\section{Medication}

Medication was measured using two questions. "In the past six months, have you taken antidepressants or sedatives?" with the response alternatives "yes" or "no". "How often do you self-medicate with nonprescription painkillers?" with response alternatives "never", "less than a few times each month", "a few times each month", "every week", and "every day". The response alternatives "every week", and "every day" were presented as "every week".

\section{Anxiety and depression}

Anxiety and depression were measured with the Hospital Anxiety and Depression Scale (HADS) developed by Zigmond and Snaith [49,50]. HADS includes two 7-item sub-scales comprising seven questions each for "anxiety" and for "depression" [49]. Each question scores 0-3 points. A total score of 0-7 points indicate "no" anxiety/ depression, 8-10 points indicates "possible" mild to moderate symptoms, and 11-21 points indicates a "probable" clinically significant condition of anxiety/ depression. HADS has been validated in adolescents with adequate test-retest reliability and factor 
Table 2 Factor analysis using a rotated component matrix for perceived stress variables (factor loading $>0.50$ is cut-off point for inclusion)

\begin{tabular}{|c|c|c|c|}
\hline \multirow[t]{2}{*}{ Perceived stress variables } & \multicolumn{3}{|c|}{ Factor loading } \\
\hline & Factor 1 & Factor 2 & Factor 3 \\
\hline Pressure and demands & $\begin{array}{c}\text { Eigenvalue } 5.97 \text { Cronbach's } \\
\text { alpha } 0.83\end{array}$ & & \\
\hline I don't have enough time & 0.754 & & \\
\hline $\begin{array}{l}\text { I feel under pressure from school } \\
\text { demands }\end{array}$ & 0.698 & & \\
\hline I feel helpless & 0.671 & & \\
\hline I never feel really free & 0.641 & & \\
\hline $\begin{array}{l}\text { I feel under pressure from demands at } \\
\text { home }\end{array}$ & 0.563 & & \\
\hline $\begin{array}{l}\text { I feel under pressure from my inner } \\
\text { demands }\end{array}$ & 0.536 & & \\
\hline I don't feel rested after sleep & 0.531 & & \\
\hline Activation/high tempo & & $\begin{array}{c}\text { Eigenvalue } 1.41 \text { Cronbach's } \\
\text { alpha } 0.72\end{array}$ & \\
\hline I rush even if I don't have to & & 0.721 & \\
\hline I keep a high speed all the day & & 0.700 & \\
\hline I eat rapidly even if I don't have to & & 0.576 & \\
\hline I do many things at the same time & & 0.551 & \\
\hline I find it difficult to relax & & 0.533 & \\
\hline Sleep problems & & & $\begin{array}{c}\text { Eigenvalue } 1.04 \text { Cronbach's } \\
\text { alpha } 0.82\end{array}$ \\
\hline I sleep restlessly and shallow & & & 0.763 \\
\hline I have difficulty falling asleep & & & 0.739 \\
\hline I wake up early in the morning & & & 0.606 \\
\hline I feel restless & & & 0.524 \\
\hline
\end{tabular}

Selected factors with an eigenvalue greater than 1 explained $52.7 \%$ of the variance.

structure [52] and has a similar sensitivity and specificity as the General Health Questionnaire (GHQ) [53]. Good psychometric properties and a two-factor structure were shown in a Swedish adult population sample [54]. In our calculations of correlations, we used the standardized two-factor structure of "anxiety" and "depression" according to Zigmond and Snaith $[49,50]$ which is the most commonly used [53]. However, other factor structures are recently discussed [55].

\section{Statistics}

Data were analyzed with the Statistical Package for the Social Sciences, version 18, SPSS Inc., Chicago, IL. Differences in proportions were evaluated using the Chisquared test. Independent sample t-tests were used to compare mean values between groups.

As described above (see Measures), an exploratory factor analysis using principal component analysis with varimax rotation and Kaiser normalisation was conducted for variables on a) subjective health complaints
(Table 1), and b) perceived stress including sleeping problems (Table 2). A cut-off point for inclusion was factor loading $>0.50$, which was the same as used by Lindblad et al. [48]. The chosen cut-off assures that the included items are clearly related to the generated factors. Cronbach's alpha was used to test reliability and values $>0.6$ were considered to indicate a sufficient degree of internal consistency.

Correlations were computed using Pearson correlation coefficients. Correlations were computed between the identified factors for subjective health complaints and perceived stress, derived from the factor analysis (Tables 1 and 2), and the standardized factors/subscales of HADS-anxiety and HADS-depression from the HADS-instrument $[49,50]$. A $p$-value $\leq 0.001$ was considered significant.

Since the data has a hierarchal structure consisting of three levels - individual, class and school - a hierarchal mixed model approach was applied to measure the proportion of explained variability at each level. Variability 
at the individual level refers to individual characteristics, whereas variability at class- or school level refers to conditions shared by all individuals in a certain class or school (e.g. teachers, pedagogy, climate, size of class/school). A variance component, the Intraclass Correlation Coefficient (ICC), was calculated for class level and school level. Dependent variables in the mixed models were the created indexes for pressure and demands, activation/high tempo, sleep problems, psychosomatic problems, headache / upper respiratory infection symptoms, musculoskeletal pain symptoms, anxiety, and depression. One covariate, sex, was used in the models.

\section{Results}

\section{Socio-demographics}

Group socio-demographics are described in Table 3. The majority of respondents were 16 or 17 years old (96.2\%), with a mean age of 16.5 years. The majority lived with their mother and father and was born in Sweden. Of the 1027 students participating, $60.7 \%$ were girls and 39.3\% were boys; $75.8 \%$ attended academic programmes and $24.2 \%$ vocational study programmes, respectively. In the academic programmes $61.8 \%$ were girls and $38.2 \%$ were boys, and within vocational programmes $56.3 \%$ were girls and 43.7\% were boys. The Chi Squared test showed no significant differences between girls and boys regarding socio-demographic characteristics.

\section{Subjective health complaints and general self-rated health}

Being tired and feeling sad were the most common subjective health complaints (Table 4). Of the girls, 38.8\% reported "fairly often/very often" feeling more tired than before compared to $20.3 \%$ of the boys $(p \leq 0.000)$. Of the girls $35.0 \%$ reported "fairly often/very often" sadness compared to $8.2 \%$ of the boys $(p \leq 0.000)$. The most common musculoskeletal problem was neck pain for girls and low back pain for boys. Three-fold more girls (33\%) reported headache than boys (11.1\%). Significantly more girls than boys reported symptoms of upper respiratory infection. It is noteworthy, that in contrast to the high prevalence of specific health complaints they reported, the majority of the adolescents rated their overall health as "good" (very good/fairly good), with significantly more boys than girls rating their health as "good". Almost 20\% of the girls took over-the-counter pain medicines every week. The use of antidepressants or sedatives was lower, with no significant differences between girls and boys.

Table 3 Socio-demographics of 1027 adolescents in grades 1 and 2 in three public upper secondary schools in northern Sweden $\left(\mathrm{Chi}^{2}\right.$ test)

\begin{tabular}{|c|c|c|c|}
\hline Socio-demographic variables & Total, n (\%) & Girls, n (\%) & Boys, n (\%) \\
\hline Sex & 1027 & $623(60.7)$ & $404(39.3)$ \\
\hline \multicolumn{4}{|l|}{ Age } \\
\hline 16 years & $562(54.8)$ & $335(59.6)$ & $227(40.4)$ \\
\hline 17 years & $425(41.4)$ & $262(61.6)$ & $163(38.4)$ \\
\hline 18 years & $39(3.8)$ & $25(64.1)$ & $14(35.9)$ \\
\hline \multicolumn{4}{|l|}{ *1 missing } \\
\hline \multicolumn{4}{|l|}{ Study programme } \\
\hline Academic programme & $774(75.8)$ & $478(61.8)$ & $296(38.2)$ \\
\hline Vocational programme & $247(24.2)$ & $139(56.3)$ & $108(43.7)$ \\
\hline \multicolumn{4}{|l|}{ *6 missing } \\
\hline \multicolumn{4}{|l|}{ Family situation } \\
\hline Living with both parents & $639(62.2)$ & $380(59.5)$ & $259(40.5)$ \\
\hline Living with only one parent & $142(13.8)$ & $87(61.3)$ & $55(38.7)$ \\
\hline Other family combination & $207(20.2)$ & $130(62.8)$ & $77(37.2)$ \\
\hline Living alone & $39(3.8)$ & $26(66.7)$ & $13(33.3)$ \\
\hline \multicolumn{4}{|l|}{ Country of birth } \\
\hline Sweden & $968(95.5)$ & $591(61.1)$ & 377 (38.9) \\
\hline Other Nordic country & $5(0.5)$ & $3(60)$ & $2(40)$ \\
\hline Europe or North America & $12(1.2)$ & $7(58.3)$ & $5(41.7)$ \\
\hline Outside Europe or North America & $29(2.9)$ & $15(51.7)$ & $14(48.3)$ \\
\hline *13 missing & & & \\
\hline
\end{tabular}

No significant differences between boys and girls. 
Table 4 Prevalence (\%) of subjective health complaints expressed as psychosomatic symptoms, headache and upper infection symptoms and musculoskeletal pain symptoms in the last six months in girls and boys

\begin{tabular}{|c|c|c|c|c|c|c|c|}
\hline \multirow[t]{2}{*}{ Subjective health complaint indexes } & \multicolumn{3}{|c|}{ Girls (\%) } & \multicolumn{3}{|c|}{ Boys (\%) } & \multirow{2}{*}{$\begin{array}{c}P- \\
\text { value }\end{array}$} \\
\hline & $\begin{array}{l}\text { Never/ } \\
\text { seldom }\end{array}$ & Sometimes & $\begin{array}{l}\text { Fairly often/very } \\
\text { often }\end{array}$ & $\begin{array}{l}\text { Never/ } \\
\text { seldom }\end{array}$ & Sometimes & $\begin{array}{l}\text { Fairly often/very } \\
\text { often }\end{array}$ & \\
\hline \multicolumn{8}{|l|}{ Psychosomatic symptoms variables $a$} \\
\hline More tired than before & 25.1 & 36.1 & 38.8 & 47.7 & 31.9 & 20.3 & 0.000 \\
\hline Sadness & 28.9 & 36.1 & 35.0 & 67.8 & 24.1 & 8.2 & 0.000 \\
\hline Acid stomach, stomach ache & 60.2 & 25.0 & 14.8 & 86.2 & 10.9 & 3.0 & 0.000 \\
\hline Pain and aches in heart and chest & 73.6 & 16.2 & 10.1 & 80.6 & 13.4 & 5.9 & 0.019 \\
\hline Palpitations and extra heart beats & 79.9 & 13.7 & 6.4 & 87.6 & 8.7 & 3.7 & 0.000 \\
\hline \multicolumn{8}{|c|}{$\begin{array}{l}\text { Headache and upper respiratory infection symptoms } \\
\text { variables a }\end{array}$} \\
\hline Headache & 34.2 & 32.6 & 33.2 & 61.4 & 27.5 & 11.1 & 0.000 \\
\hline Cold symptoms & 38.3 & 36.5 & 25.2 & 58.9 & 27.7 & 13.4 & 0.000 \\
\hline Cough and hoarseness & 61.9 & 26.5 & 11.6 & 75.5 & 18.6 & 5.9 & 0.000 \\
\hline Nausea & 58.3 & 26.2 & 15.6 & 86.8 & 10.4 & 2.7 & 0.000 \\
\hline \multicolumn{8}{|l|}{ Musculoskeletal pain symptoms variables ${ }^{a}$} \\
\hline Neck and shoulder pain & 40.1 & 25.4 & 34.5 & 67.5 & 21.4 & 10.9 & 0.000 \\
\hline Low back pain & 52.3 & 23.5 & 24.2 & 68.2 & 16.8 & 15.0 & 0.000 \\
\hline Pain in extremity joints & 65.0 & 22.3 & 12.7 & 71.5 & 18.6 & 9.9 & 0.079 \\
\hline Muscle pain & 64.4 & 25.6 & 10.0 & 71.0 & 20.5 & 8.4 & 0.05 \\
\hline \multicolumn{8}{|l|}{ General self-rated health ${ }^{\mathbf{b}}$} \\
\hline Overall good health & 79.5 & & & 87.8 & & & 0.000 \\
\hline \multicolumn{8}{|l|}{ Medication $^{\mathbf{b}}$} \\
\hline Antidepressants or sedatives (yes) & 4.7 & & & 3.5 & & & 0.3 \\
\hline Non-prescription painkillers, every week & 17.9 & & & 7.2 & & & 0.000 \\
\hline
\end{tabular}

Response alternatives were "never/seldom", "sometimes", and "fairly often/very often" (Chi test with p-values for between group differences).

aSubjective health complaint indexes included variables yielded from factor analysis (see Table 1). ${ }^{b}$ General self-rated health and medication not included in the factor analysis.

\section{Perceived stress}

For all of the stress variables, more girls than boys reported significantly more perceived stress (Table 5). More than half of boys and girls "often/always" perceived demands from school as stressful, and many girls also perceived high inner demands in that way, while few girls and boys perceived demands from home as stressful. Over half (54.7\%) of the girls never felt really free, and there were more girls than boys who reported doing many things at the same time. Many girls reported eating rapidly even when they did not have to, and more girls than boys had difficulty in relaxing. Difficulty in falling asleep at night and helplessness were reported more often among girls than boys.

\section{Anxiety and depression}

Overall, these adolescents scored higher on the HADS-anxiety scale than on the HADS-depression scale (Table 6). Of the girls, $31.5 \%$ scored as "possible" and $27 \%$ as "probable" anxiety compared to $21.1 \%$ with "possible" and $8.7 \%$ with "probable" anxiety among the boys. According to the independent sample t-test, sex/gender differences in signs of depression were small and non-significant. Of the girls, $10 \%$ scored as "possible" and $4.1 \%$ as "probable" depression compared to $7.9 \%$ and $2.5 \%$, respectively, among the boys.

\section{Correlations}

Subjective health complaints correlated significantly with all factors of perceived stress, anxiety and depression, and vice versa (see Correlation matrix, Table 7). The strongest correlations were found between the factors "psychosomatic complaints" and "anxiety" $(\mathrm{r}=0.71)$, and between perceived stress expressed as "pressure and demands" and "anxiety" $(\mathrm{r}=0.71)$. Perceived stress in the form of "pressure and demands" was also significantly correlated with "activation/high tempo" $(r=0.68)$, 
Table 5 Prevalence (\%) of perceived stress expressed as pressure and demands, activation/high tempo and sleep problems during the previous weeks in girls and boys

\begin{tabular}{|c|c|c|c|c|c|c|c|}
\hline \multirow[t]{2}{*}{ Perceived stress indexes a } & \multicolumn{3}{|c|}{ Girls (\%) } & \multicolumn{3}{|c|}{ Boys (\%) } & \multirow[t]{2}{*}{$P$-value } \\
\hline & Never/seldom & Sometimes & Often/always & Never/seldom & Sometimes & Often/always & \\
\hline \multicolumn{8}{|l|}{ Pressure and Demands variables $a$} \\
\hline I don't have enough time & 28.4 & 38.3 & 33.4 & 39.4 & 38.4 & 22.3 & 0.000 \\
\hline I feel under pressure from school demands & 9.8 & 26.6 & 63.6 & 26.1 & 35.5 & 38.5 & 0.000 \\
\hline I feel helpless & 58.9 & 27.1 & 14.0 & 79.0 & 16.3 & 4.7 & 0.000 \\
\hline I never feel really free & 19.8 & 25.5 & 54.7 & 37.1 & 27.2 & 35.6 & 0.000 \\
\hline I feel under pressure from demands at home & 63.0 & 20.6 & 16.4 & 74.2 & 13.9 & 11.9 & 0.003 \\
\hline I feel under pressure from my inner demands & 18.3 & 25.7 & 56.1 & 38.9 & 33.2 & 28.0 & 0.000 \\
\hline I don't feel rested after sleep & 20.7 & 29.7 & 49.6 & 34.6 & 28.0 & 37.4 & 0.000 \\
\hline \multicolumn{8}{|l|}{ Activation/High tempo variables a } \\
\hline I rush even if I don't have to & 35.0 & 33.7 & 31.3 & 62.6 & 26.8 & 10.7 & 0.000 \\
\hline I keep a high speed all the day & 35.9 & 39.6 & 24.5 & 62.4 & 23.8 & 13.9 & 0.000 \\
\hline I eat rapidly even if I don't have to & 31.7 & 29.4 & 39.0 & 43.1 & 25.0 & 32.0 & 0.006 \\
\hline I do many things at the same time & 13.0 & 34.1 & 52.8 & 28.0 & 40.8 & 31.2 & 0.000 \\
\hline I find it difficult to relax & 27.1 & 39.8 & 33.1 & 57.3 & 28.5 & 14.1 & 0.000 \\
\hline \multicolumn{8}{|l|}{ Sleep problems variables ${ }^{a}$} \\
\hline I sleep restlessly and shallow & 60.1 & 25.2 & 14.6 & 77.5 & 16.9 & 5.7 & 0.000 \\
\hline I have difficulty falling asleep & 40.0 & 32.1 & 28.0 & 54.7 & 22.3 & 23 & 0.000 \\
\hline I wake up early in the morning & 72.6 & 16.1 & 11.4 & 83.6 & 9.4 & 6.9 & 0.000 \\
\hline I feel restless & 28.4 & 50.4 & 21.2 & 36.7 & 47.1 & 16.1 & 0.035 \\
\hline
\end{tabular}

Response alternatives were "never/seldom", "sometimes" and "often/always" (Chi ${ }^{2}$ test with p-values for between group differences).

aperceived stress index included variables yielded from factor analysis. (see Table 2).

"psychosomatic problems" ( $r=0.63)$, "depression" $(r=0.52)$, sleep problems $(\mathrm{r}=0.48)$, "headache/upper respiratory infections" ( $r=0.48)$ and "musculoskeletal pain symptoms"

Table 6 Prevalence (\%) of self-reported anxiety and depression according to the Hospital Anxiety and Depression Scale (mean, SD) in girls and boys (independent sample t-test)

\begin{tabular}{llcc}
\hline HADS & Girls & Boys & P-value \\
\hline HADS-anxiety & & & $0.001^{*}$ \\
Total score (mean, SD) & $8.5 \pm 3.8$ & $5.8 \pm 3.3$ & \\
Severity (score range) & & & \\
Normal (1-7 points) (\%) & 41.5 & 70.1 & \\
Possible (8-10 points) (\%) & 31.5 & 21.1 & \\
Probable (11-21 points) (\%) & 27.0 & 8.7 & \\
HADS-depression & & & \\
Total score (mean, SD) & $4.1 \pm 3.0$ & $3.5 \pm 2.7$ & \\
Severity (score range) & & & \\
Normal (1-7 points) (\%) & 85.9 & 89.6 & \\
Possible (8-10 points) (\%) & 10.0 & 7.9 & \\
Probable (11-21 points) (\%) & 4.1 & 2.5 & \\
\hline
\end{tabular}

*Statistically significant difference at $p \leq 0.001$. $(\mathrm{r}=0.44)$. "Sleep problems" strongly correlated with "psychosomatic problems" $(\mathrm{r}=0.56)$, "anxiety" $(\mathrm{r}=0.53)$ and stress expressed as "activation/high tempo" $(\mathrm{r}=0.50)$. The psychological factors of "anxiety" and "depression" from HADS were also significantly correlated to each other $(r=0.56)$.

\section{Hierarchal mixed model analysis}

According to the hierarchal mixed model analysis $96-100 \%$ of the total variability in the outcome indexes can be explained by individual-level characteristics, such as sex/gender, and not by factors at class- or school-level. The class level and the school level explained $0.6-3.8 \%$ (ICC 0.006-0.038) and 0-2.3\% (ICC 0-0.023), respectively. Differences between boys and girls remained statistically significant in all outcome indexes even after calculating the proportion of variance at all hierarchal levels.

\section{Discussion}

The main finding in this study among older adolescents is the high prevalence of subjective health complaints and perceived stress, especially among the girls. For nearly all complaints, the proportion of girls reporting 
Table 7 Correlations between factors/indexes of perceived stress (pressure and demands; activation/high tempo), sleep, subjective health complaints (headache/upper respiratory infections; musculoskeletal pain), anxiety and depression in adolescents (Pearson correlation coefficients)

\begin{tabular}{|c|c|c|c|c|c|c|c|c|}
\hline Factors/Indexes & $\begin{array}{l}\text { Pressure and } \\
\text { demands }\end{array}$ & $\begin{array}{l}\text { Activation } \\
\text { /high tempo }\end{array}$ & $\begin{array}{c}\text { Sleep } \\
\text { problems }\end{array}$ & $\begin{array}{l}\text { Psycho- } \\
\text { somatic }\end{array}$ & $\begin{array}{l}\text { Headache /upper } \\
\text { respiratory infections }\end{array}$ & $\begin{array}{l}\text { Musculo- } \\
\text { skeletal pain }\end{array}$ & $\begin{array}{l}\text { HADS- } \\
\text { anxiety }\end{array}$ & $\begin{array}{l}\text { HADS- } \\
\text { depression }\end{array}$ \\
\hline Pressure and demands & 1 & 0.68 & 0.48 & 0.63 & 0.48 & 0.44 & 0.71 & 0.52 \\
\hline Activation/high tempo & 0.68 & 1 & 0.50 & 0.55 & 0.44 & 0.39 & 0.66 & 0.39 \\
\hline Sleep problems & 0.48 & 0.50 & 1 & 0.56 & 0.41 & 0.44 & 0.53 & 0.39 \\
\hline Psychosomatic & 0.63 & 0.55 & 0.56 & 1 & 0.58 & 0.55 & 0.71 & 0.49 \\
\hline $\begin{array}{l}\text { Headache/upper } \\
\text { respiratory infections }\end{array}$ & 0.48 & 0.44 & 0.41 & 0.58 & 1 & 0.51 & 0.52 & 0.35 \\
\hline Musculoskeletal pain & 0.44 & 0.39 & 0.44 & 0.55 & 0.51 & 1 & 0.45 & 0.30 \\
\hline HADS-anxiety & 0.71 & 0.66 & 0.53 & 0.71 & 0.52 & 0.45 & 1 & 0.56 \\
\hline HADS-depression & 0.52 & 0.39 & 0.39 & 0.49 & 0.35 & 0.30 & 0.56 & 1 \\
\hline
\end{tabular}

All correlations were statistically significant at $p \leq 0.001$.

"often" or "always" was two to three times higher than among boys. Perceived stress was associated with both physical and psychosomatic symptoms, including sleep problems and psychological symptoms of anxiety and depression. However, the strongest associations were found between perceived stress, psychosomatic symptoms and anxiety. The consistent pattern of gender differences in subjective health and physical and psychological health complaints are in line with findings from several previous national and international studies on young adolescent subjective health $[7-10,19,35]$. The results of our study indicate that negative trends in subjective health among girls that start in early adolescence seem to persist in late adolescence. It is noteworthy that although there were high levels of subjective health complaints and perceived stress, the majority $(83.6 \%)$ rated their overall health as "fairly good/very good". This is similar to a Norwegian study where $88 \%$ of the students (16-20 years) rated their health as "good" or "very good" [51].The interpretation of this might be that the symptoms reported, although frequent, are not severe enough to have a significant negative effect on "health", as characterized by the adolescents. Alternatively, adolescents may interpret "good health" simply as "not being physically sick". Their definition of health may not include their perceptions of general wellbeing or mental illness. In comparison, Breidablik et al. [51] suggest that adolescents incorporate a broad health definition when describing their health, and that their constructs of selfrated health are associated with several medical, social and psychological background factors. Since self-rated health is seen as an important health indicator, both positive and negative self-rated health during adolescence need to be further studied [51,56,57].

Another finding was that nearly $63.6 \%$ of the girls and $38.5 \%$ of the boys "often" or "always" perceived as stressful, forms of high pressures and demands from school.
The proportion perceiving demands from home in this way was much lower. Thus, the school environment and/or school-work is an important possible stressor and this finding is in line with earlier studies on schoolrelated stress and health $[13,24,58]$. Perceptions of high self-imposed demands and inner pressure were common, especially among the girls. Similar perceptions of high self-imposed demands and distress were illuminated in a qualitative study comprising young women, aged 16-25 years, who had sought help for stressrelated problems [31]. More girls than boys reported helplessness, which can be interpreted as a marker for a low degree of control and perceived inability to handle their situation. This may indicate poor social support. This is consistent with the definition of increased stress as a situation or condition where perceived demands exceed perceived resources and coping abilities [59]. In addition, it reveals lack of individual power and control, which seems to be a key factor relating to girls' self-esteem and health $[58,60]$.

Also according with our findings, perceived high demands in school and high responsibility-taking have been highlighted as possible stressors and contributors to mental strain in adolescent girls [31,34]. Qualitative studies have illuminated how boys experience fewer demands and less pressure to perform well, and do not report multiple demands as often as girls do [60]. Furthermore, responsibilitytaking is interpreted as a power-negotiation strategy for girls in school [60]. Girls seem to take a great deal responsibility for schoolwork as well for other concurrent duties in life [31]. Several studies, point to the importance of balance between demands, control and support for adolescent health and well-being $[19,58]$.

One striking result was the high prevalence of anxiety among both boys and girls, although this was more 
pronounced among girls. In comparison with a control sample of secondary school girls in a study by Blom et al. [61], the girls in our study had a higher mean value of anxiety. Increased levels of anxiety, as measured by the HAD-scale, may be an aspect of high stress arousal, as this correlates well with the stress indexes of "pressure and demands" and "activation/high tempo". Anxiety also correlates with the psychosomatic symptom index consisting of both mental and physical symptoms. This relation between symptoms can be interpreted as a starting-point for stress-related disorders. The rate of depression was lower than that of anxiety. It is possible that the cut-off of eight for possible depression was set too high. White et al. [52] recommend cut-offs of seven (possible mild/moderate depression) and nine (probable clinically significant depression) to capture depression in early stages among adolescents. Reporting feeling tired and sad may be an expression of a depressive mood and warrants attention to the possible development of more severe stress-related disorders and mental ill-health. Aalto-Setälä et al. [62] examined mental health risks in adolescence and found that girls were more likely to be distressed than boys, and that high trait anxiety and somatic symptom scores among adolescents predicted mental distress among women. A longitudinal study [63] found that perceived nervousness and anxiety were strong predictors of premature mortality and psychiatric disorders. Anxiety disorders most typically have their onset in childhood or adolescence [28], and are therefore important to capture in early stages.

Consequently, the strong associations between pressures and demands, activation/high tempo and physical and psychological symptoms must be interpreted as a negative health pattern. Moreover these findings are emphasized by the presence of sleeping problems, as stress impairs sleep. Our results show slightly higher prevalence of sleep-onset difficulties than a study of 15-year olds in Norway [41]. However, that study adressed younger adolescents and may have used a stricter cut-off for sleeponset difficulties. These signs of sleep-related problems may be related to mental health [64], but also to psycho-physiological strain and theories of allostatic load [65], as these processes may result in chronic deterioration of cardiovascular, immune, gastrointestinal and cognitive systems, in the long run. Long-term effects of this type of strain in young age groups are less understood, although relationships between psychosocial stress in childhood and increased stress-responses have been found [66]. Moreover, pain problems and sleeping disturbances starting during childhood and adolescence tend to persist into adulthood $[39,40]$. In line with the present study, recent studies have addressed severe stress-related disorders of school-burnout [13] and chronic stress [19] among older adolescents.
One key question is why girls report more pressures and demands, stress, and health complaints than boys do. Explanations suggested on both individual and societal levels, include Hyde et al.'s [67] model in which biological, affective, and cognitive vulnerabilities in females interact with negative life-events. Pubertal timing has been investigated in relation to emotional distress in girls [68] and early puberty has been linked to various problem-behaviors [69]. Stattin et al. [69] emphasize the role of contextual mechanisms such as peer-socialization in understanding external problem behavior. Earlier explanatory models, such as the symptom perception theory, emphasize gender differences according to how individuals pay attention to, define and react to symptoms [35,70]; whereas interpersonal stress models focus on girls' vulnerability to emotional distress connected to social relationships [71].

In contrast, socially-oriented models highlight the importance of contextualizing adolescent distress, including social aspects of performing and constructing gender, and also address unequal power relations $[31,34,60]$. Girls may develop multiple stress complaints as a result of psychosocial stressors in the environment. The transition to adulthood is a period when adolescent girls seem to encounter socially shaped contradicting expectations and rapidly expanding roles that may be stressful and difficult to manage, particularly if social support is inadequate [31]. Furthermore, Maclean et al. [72] discuss differences in symptom-reporting in relation to gender stereotypes, and conclude that according to norms of masculinity, boys seem reluctant to report health complaints, whereas girls have more complex patterns of symptom-reporting. They also point to similarities, since both boys and girls felt pressured to react to symptoms in a "stoic" way. Hagquist [6] proposes the inclusion of both internalizing and externalizing problems when measuring adolescent mental health, because boys tend to report more externalizing problems and girls more internalizing problems. However, these complex gender-related patterns need to be further addressed. Future studies should pay attention to the balance between gender-related demands, perceived control, and social support, particularly in the school environment, in order to prevent negative strain and stress-related ill-health.

\section{Limitations and strengths}

This study has both a number of limitations, and strengths that are relevant to the interpretation and robustness of the results. Firstly, the cross-sectional design has its given limitations. Since cross-sectional data represent a "snapshot in time", our results cannot indicate (one-way directional) causality or symptom development over time. Accordingly, the present results do not explain whether 
perceived stress caused health complaints, or vice versa. Instead, this study shows significant gender differences in prevalence of perceived stress and interesting (bi-directional) symptom patterns. However, based on results from other studies $[24,73,74]$ and our own clinical experience, we hypothesize that perceived stress and demands may be important explanatory factors in the reported physical/ psychological symptoms. Associations between perceived stressors and demands and physical/psychological symptoms are findings of importance to worth further in-depth attention in future studies. Little is still known about longterm consequences of stress and gendered patterns of "school burnout" at young ages [13,19,31].

Another element of uncertainty is how representative the studied group is of a broader population of adolescents, as the sample was limited to three schools in northern Sweden. There was an overrepresentation of girls, particularly in academic programmes; and an underrepresentation of boys, particularly in vocational programmes, as all of the students at the invited schools were not approachable at the time of the survey. The reasons for this were firstly that the study was performed within the constraints of a school setting, and secondly, that we chose to conduct a class-room survey. Teachers had difficulties allocating time for the survey due to a tight schedule, and potential participants at vocational programmes were not approachable because of work placement periods. Furthermore, non-participants could not be reached and analysis of the non-participants was not possible as, for ethical reasons, no record of respondent names was compiled.

However, even given these weaknesses, the participating students represented a relatively large sample of 16-18 years old boys and girls from 49 different classes attending a wide range of educational programmes, both vocational and academic, at the largest public upper secondary schools in the geographical area. A strength of the study that may be connected to the class-room procedure, is its high response rate and low level of missing data. An additional strength is that the questionnaire covered a wide range of physical and mental complaints, including perceived stress, sleep, pain, anxiety and depression - symptoms that are found to be potential predictors for development of prolonged problems or psychiatric problems $[39,40,42-44]$. The use of an established instrument for measuring anxiety and depression contributed to the value of the knowledge derived.

\section{Conclusions}

In conclusion, this study of older adolescents found significant differences between boys and girls in their subjective health and perceived stress. Both boys and girls experienced stress in the form of high pressure and demands from school which were strongly associated with psychosomatic symptoms and anxiety. The results may indicate a trend toward increased symptoms of severe stress-related disorders, especially among girls. Furthermore, perceived stress, pressure and demands may be important explanatory factors. However, further exploration is needed of how cultural norms and gender-related expectations, including those of the school environment, affect adolescent stress and health.

\section{Competing interests}

No competing interests.

\section{Authors' contributions}

All authors contributed to the study's design, the interpretation of data and to the critical revision of the manuscript. MW, EBMO, AÖ and AFW were responsible for contacts with the schools and school-health services, as well as for the data-collection procedure. MW, EBMO and AFW prepared the data, performed the statistical analysis, and drafted the manuscript. All authors read and approved the final manuscript.

\section{Acknowledgements}

We thank all survey participants, school staff, project assistants, and the School Health Services, Umeå. We also thank statistician Hans Stenlund for his help with the statistics. Financial support was provided by the Västerbotten County Council, the Swedish Research Institute (no. 521-20054848), Umeå Municipality (TILDA), and the Umeå Centre for Global Health Research with grants from the Swedish Council of Working Life and Social Research (no. 2006-1512), Umeå University, Sweden.

\section{Author details}

${ }^{1}$ Umeå Center for Gender Studies, Umeå University, Umeå, Sweden. 2Department of Community Medicine and Rehabilitation, Physiotherapy, Umeå University, Umeå, Sweden. ${ }^{3}$ Department of Public Health and Clinical Medicine, Epidemiology and Global Health, Umeå University, Umeå, Sweden. ${ }^{4}$ Department of Clinical Sciences, Pediatrics, Umeå University, Umeå, Sweden.

Received: 27 April 2012 Accepted: 14 November 2012

Published: 16 November 2012

\section{References}

1. Patel V, Flisher AJ, Hetrick S, McGorry P: Mental health of young people: a global public-health challenge. Lancet 2007, 369(9569):1302-1313.

2. Ravens-Sieberer U, Torsheim T, Hetland J, Vollebergh W, Cavallo F, Jericek $H$, Alikasifoglu M, Välimaa R, Ottova V, Erhart $M$, et al: Subjective health, symptom load and quality of life of children and adolescents in Europe. Int J Public Health 2009, 54:151-159.

3. Patton GC, Viner R: Pubertal transitions in health. Lancet 2007, 369 (9567):1130-1139.

4. Gore FM, Bloem PJN, Patton GC, Ferguson J, Joseph V, Coffey C, Sawyer SM, Mathers CD: Global burden of disease in young people aged 10-24 years: a systematic analysis. Lancet 2011, 377(9783):2093-2102

5. Petersen S, Bergström E, Cederblad M, Ivarsson A, Köhler L, Rydell A-M, Stenbeck M, Sundelin C, Hägglöf B: Barns och ungdomars psykiska hälsa i Sverige. En systematisk litteraturöversikt med tonvikt på förändringar över tid [Trends in Child and Adolescent Mental Health in Sweden. A systematic review]. Stockholm: The Royal Swedish Academy of Sciences, The Health Committee; 2010.

6. Hagquist C: Discrepant Trends in Mental Health Complaints Among Younger and Older Adolescents in Sweden: An Analysis of WHO Data 1985-2005. J Adolescent Health 2010, 46(3):258-264.

7. National Board of Health and Welfare: Public Health Report. In Edited by Ministry of Health and Social Affairs. Stockholm: The Centre for Epidemiology; 2009.

8. Friberg P, Hagquist C, Osika W: Self-perceived psychosomatic health in Swedish children, adolescents and young adults: an internet-based survey over time. BMJ Open 2012, 2(e000681):1-6. doi:10.1136/ bmjopen-2011-000681. 
9. Hagquist C: Psychosomatic health problems among adolescents in Sweden-are the time trends gender related? Eur J Public Health 2009, 19(3):331-336

10. Torsheim T, Ravens-Sieberer U, Hetland J, Välimaa R, Danielson M, Overpeck $\mathrm{M}$ : Cross-national variation of gender differences in adolescent subjective health in Europe and North America. Soc Sci Med 2006, 62(4):815-827.

11. Michel G, Bisegger C, Fuhr D, Abel T, The Kidscreen Group: Age and gender differences in health-related quality of life of children and adolescents in Europe: a multilevel analysis. Qual Life Res 2009, 18(9):1147-1157.

12. Haugland S, Wold B: Subjective health complaints in adolescenceReliability and validity of survey methods. J Adolescence 2001, 24(5):611-624.

13. Salmela-Aro K, Tynkkynen L: Gendered pathways in school burnout among adolescents. J Adolescence 2012, 35(4):929-939.

14. Collishaw S, Maughan B, Goodman R, Pickles A: Time trends in adolescent mental health. J Child Psychol Psyc 2004, 45(8):1350-1362.

15. Maughan B, Collishaw S, Meltzer H, Goodman R: Recent trends in UK child and adolescent mental health. Soc Psych Psych Epid 2008, 43(4):305-310.

16. Tick N, van der Ende J, Verhulst F: Ten-year trends in self-reported emotional and behavioral problems of Dutch adolescents. Soc Psych Psych Epid 2008, 43(5):349-355.

17. SOU: Ungdomar, stress och psykisk ohälsa: Analyser och förslag till åtgärder. Slutbetänkande. Utredningen om ungdomars psykiska hälsa [Young people, stress and mental health]. Stockholm: Swedish Government Official Report; 2006.

18. Statistics Sweden: Undersökning av levnadsförhållanden bland barn 2009 [Survey of living conditions among children, 2009]. SCB: Stockholm; 2009.

19. Schraml K, Perski A, Grossi G, Simonsson-Sarnecki M: Stress symptoms among adolescents: The role of subjective psychosocial conditions, lifestyle, and self-esteem. J Adolescence 2011, 34(5):987-996.

20. Arnett JJ: Emerging adulthood: A theory of development from the late teens through the twenties. Am Psychol 2000, 55(5):469-480.

21. Byrne DG, Davenport SC, Mazanov J: Profiles of adolescent stress: The development of the adolescent stress questionnaire (ASQ). J Adolescence 2007, 30(3):393-416.

22. Arnett JJ: Adolescent storm and stress, reconsidered. Am Psychol 1999, 54(5):317-326.

23. Modin B, Ostberg V, Almquist $Y$ : Childhood peer status and adult susceptibility to anxiety and depression. A 30-year hospital follow-up. J Abnorm Child Psychol 2010, 39:187-199.

24. Hjern A, Alfven G, Östberg V: School stressors, psychological complaints and psychosomatic pain. Acta Paediatr 2008, 97:(1)112-117.

25. Jablonska B, Lindblad F, Ostberg V, Lindberg L, Rasmussen F, Hjern A: A national cohort study of parental socioeconomic status and nonfatal suicidal behaviour-the mediating role of school performance. BMC Publ Health 2012, 12(1):17

26. Nygren K, Bergstrom E, Janlert U, Nygren L: Parents matter - but relations to parents do not explain gender differences in selfreported health in adolescents. Scand J Caring Sci 2012, 26(4):643-653.

27. Wiklund M, Malmgren-Olsson E-B, Bengs C, Öhman A: "He messed me up": Swedish adolescent girls' experiences of gender-related partner violence and its consequences over time. Violence Against Wom 2010, 16:(2)207-232

28. Kessler R, Berglund P, Demler O, Jin R, Merikangas KR, Walters EE: Lifetime prevalence and age-of-onset distributions of dsm-iv disorders in the national comorbidity survey replication. Arch Gen Psychiat 2005, 62(6):593-602

29. Frisén A: Measuring health-related quality of life in adolescence. Acta Paediatr 2007, 96(7):963-968.

30. Frisén A, Bjarnelind S: Health-related quality of life and bullying in adolescence. Acta Paediatr 2010, 99(4):597-603.

31. Wiklund $M$, Bengs $C$, Malmgren-Olsson EB, Öhman A: Young women facing multiple and intersecting stressors of modernity, gender orders and youth. Soc Sci Med 2010, 71(9):1567-1575.

32. Furlong A: Handbook of youth and young adulthood: new perspectives and agendas. Milton Park, Abingdon, Oxon: Routledge; 2009.

33. Landstedt E, Gadin KG: Seventeen and stressed - Do gender and class matter? Health Sociol Rev 2012, 21(1):82-98.
34. Landstedt E, Asplund K, Gillander Gådin K: Understanding adolescent mental health: the influence of social processes, doing gender and gendered power relations. Sociol Health III 2009, 31(7):962-978.

35. Hetland J, Torsheim T, Aaro LE: Subjective health complaints in adolescence: dimensional structure and variation across gender and age. Scand J Public Health 2002, 30(3):223-230.

36. Torsheim T, Wold B: School-related stress, support, and subjective health complaints among early adolescents: a multilevel approach. J Adolescence 2001, 24(6):701-713.

37. Haugland S, Wold B, Stevenson J, Aaroe L, Woynarowska B: Subjective health complaints in adolescence. Eur J Public Health 2001, 11(1):4-10.

38. Petersen S, Hagglöf BL, Bergström El: Impaired Health-Related Quality of Life in Children With Recurrent Pain. Pediatrics 2009, 124(4):e759-e767.

39. Brattberg G: Do pain problems in young school children persist into early adulthood? A 13-year follow-up. Eur J Pain 2004, 8(3):187-199.

40. Dregan A, Armstrong D: Adolescence Sleep Disturbances as Predictors of Adulthood Sleep Disturbances - A Cohort Study. J Adolescent Health 2010, 46(5):482-487

41. Pallesen S, Hetland J, Sivertsen B, Samdal O, Torsheim T, Nordhus $\mid H$ : Time trends in sleep-onset difficulties among Norwegian adolescents: 1983-2005. Scand J Public Health 2008, 36(8):889-895.

42. Baglioni C, Battagliese G, Feige B, Spiegelhalder K, Nissen C, Voderholzer U, Lombardo C, Riemann D: Insomnia as a predictor of depression: A metaanalytic evaluation of longitudinal epidemiological studies. $J$ Affect Disorders 2011, 135(1-3):10-19.

43. Clark C, Rodgers B, Caldwell T, Power C, Stansfeld S: Childhood and adulthood psychological ill health as predictors of midlife affective and anxiety disorders: The 1958 british birth cohort. Arch Gen Psychiat 2007, 64(6):668-678

44. Fergusson D, Horwood L, Ridder EM, Beautrais AL: Subthreshold depression in adolescence and mental health outcomes in adulthood. Arch Gen Psychiat 2005, 62(1):66-72

45. Nygren K, Janlert U, Nygren L: Norm compliance and self-reported health among Swedish adolescents. Scand J Public Health 2011, 39(1):44-50.

46. Petersen $\mathrm{S}$, Bergström $\mathrm{E}$, Brulin C: High prevalence of tiredness and pain in young schoolchildren. Scand J Public Health 2003, 31(5):367-374.

47. Petersen S, Brulin C, Bergström E: Recurrent pain symptoms in young schoolchildren are often multiple. Pain 2006, 121(1-2):145-150.

48. Lindblad F, Backman L, Åkerstedt T: Immigrant girls perceive less stress. Acta Paediatr 2008, 97(7):889-893.

49. Snaith RP: The Hospital Anxiety And Depression Scale. Health Qual Life Out 2003, 1(1):29.

50. Zigmond AS, Snaith RP: The Hospital Anxiety and Depression Scale. Acta Psychiat Scand 1983, 67(6):361-370.

51. Breidablik H-J, Meland E, Lydersen S: Self-rated health in adolescence: A multifactorial composite. Scand J Public Health 2008, 36(1):12-20.

52. White $D$, Leach $C$, Sims $R$, Atkinson M, Cottrell D: Validation of the Hospital Anxiety and Depression Scale for use with adolescents. Br J Psychiatry 1999, 175:452-454.

53. Bjelland I, Dahl AA, Haug TT, Neckelmann D: The validity of the Hospital Anxiety and Depression Scale: An updated literature review. J Psychosom Res 2002, 52(2):69-77.

54. Lisspers J, Nygren A, Söderman E: Hospital Anxiety and Depression Scale (HAD): some psychometric data for a Swedish sample. Acta Psychiat Scand 1997, 96(4):281-286

55. Cosco TD, Doyle F, Ward M, McGee H: Latent structure of the Hospital Anxiety And Depression Scale: A 10-year systematic review. J Psychosom Res 2012, 72(3):180-184

56. Manor O, Matthews S, Power C: Self-rated health and limiting longstanding illness: inter-relationships with morbidity in early adulthood. Int J Epidemiol 2001, 30(3):600-607.

57. Jerdén L, Burell G, Stenlund H, Weinehall L, Bergström E: Gender Differences and Predictors of Self-Rated Health Development Among Swedish Adolescents. J Adolescent Health 2011, 48(2):143-150.

58. Gillander Gådin K: School-related health--a cross-sectional study among young boys and girls. Int J Health Serv 2000, 30(4):797

59. Lazarus RS, Folkman S: Stress, Appraisal and Coping. New York: Guilford; 1984 
60. Gillander Gådin K, Hammarstrom A: 'We won't let them keep us quiet ...' Gendered strategies in the negotiation of power-implications for pupils' health and school health promotion. Health Promot Int 2000, 15(4):303-311.

61. Blom EH, Larsson JO, Serlachius E, Ingvar M: The differentiation between depressive and anxious adolescent females and controls by behavioural self-rating scales. J Affect Disord 2010, 122(3):232-240.

62. Aalto-Setala T, Poikolainen K, Tuulio-Henriksson A, Marttunen M, Lonnqvist J: Predictors of mental distress in early adulthood: a five-year follow-up of 709 high-school students. Nord J Psychiatry 2002, 56(2):121-125.

63. Ringbäck Weitoft $G$, Rosén $M$ : Is perceived nervousness and anxiety a predictor of premature mortality and severe morbidity? A longitudinal follow up of the Swedish survey of living conditions. J Epidemiol Commun H 2005, 59(9):794-798.

64. Saxvig IW, Pallesen S, Wilhelmsen-Langeland A, Molde H, Bjorvatn B: Prevalence and correlates of delayed sleep phase in high school students. Sleep Med 2012, 13(2):193-199.

65. McEwen BS: Protective and Damaging Effects of Stress Mediators. N Engl $J$ Med 1998, 338(3):171-179.

66. Gustafsson P: Psychosocial stress, mental health and salivary cortisol in children and adolescents. Linköping: Linköping university; 2008.

67. Hyde JS, Mezulis AH, Abramson LY: The ABCs of depression: integrating affective, biological, and cognitive models to explain the emergence of the gender difference in depression. Psychol Rev 2008, 115(2):291-313

68. Lien L, Dalgard F, Heyerdahl S, Thoresen M, Bjertness E: The relationship between age of menarche and mental distress in Norwegian adolescent girls and girls from different immigrant groups in Norway: results from an urban city cross-sectional survey. Soc Sci Med 2006, 63(2):285-295.

69. Stattin H, Kerr M, Skoog T: Early Pubertal Timing and Girls' Problem Behavior: Integrating Two Hypotheses. J Youth Adolescence 2011, 40(10):1271-1287

70. van Wijk CM, Kolk AM: Sex differences in physical symptoms: the contribution of symptom perception theory. Soc Sci Med 1997, 45(2):231-246.

71. Rudolph KD: Gender differences in emotional responses to interpersonal stress during adolescence. J Adolesc Health 2002, 30(4 Suppl):3-13.

72. Maclean A, Sweeting H, Hunt K: 'Rules' for boys, 'guidelines' for girls: Gender differences in symptom reporting during childhood and adolescence. Soc Sci Med 2010, 70(4):597-604

73. Alfven $G$, Östberg V, Hjern A: Stressor, perceived stress and recurrent pain in Swedish schoolchildren. J Psychosom Res 2008, 65(4):381-387.

74. Modin B, Östberg V, Toivanen S, Sundell K: Psychosocial working conditions, school sense of coherence and subjective health complaints. A multilevel analysis of ninth grade pupils in the Stockholm area. $J$ Adolescence 2011, 34(1):129-139.

doi:10.1186/1471-2458-12-993

Cite this article as: Wiklund et al: Subjective health complaints in older adolescents are related to perceived stress, anxiety and gender - a cross-sectional school study in Northern Sweden. BMC Public Health 2012 12:993

\section{Submit your next manuscript to BioMed Central and take full advantage of:}

- Convenient online submission

- Thorough peer review

- No space constraints or color figure charges

- Immediate publication on acceptance

- Inclusion in PubMed, CAS, Scopus and Google Scholar

- Research which is freely available for redistribution 